\title{
Anterior Spinal Artery as a Collateral Channel in Patients With Acute Bilateral Vertebral Artery Occlusions
}

\author{
-Two Case Reports-
}

\author{
Haruki YAMAKAWA, Shinichi YOSHIMURA, and Toru IWAMA \\ Department of Neurosurgery, Gifu University Graduate School of Medicine, Gifu
}

\begin{abstract}
Retrograde flow through the anterior spinal artery (ASA) from the cervical vertebral artery (VA) to the intracranial distal VA due to disrupted perfusion caused by bilateral VA occlusion is rare. We report two cases of hemodynamic vertebrobasilar circulatory insufficiency caused by bilateral VA occlusion. In these patients, the ASA filled in the retrograde direction, and provided collateral support to the ipsilateral posterior inferior cerebellar artery. The patients were treated with drip intravenous infusion of edaravone and/or argatroban. One patient had a good collateral supply from the posterior communicating artery and recovered almost completely within one month, but the other did not and lapsed into a coma, with generalized hyperreflexia, pin-point pupils, and ataxic respiration. Severe calcified lesions on three-dimensional computed tomography angiography at the occlusion site in the second patient indicated direct surgery including right superficial temporal artery to superior cerebellar artery anastomosis, rather than the endovascular approach. Retrograde flow through the ASA may be observed in this type of critical situation, and may be an important source of collateral supply to the posterior fossa territory.
\end{abstract}

Key words: anterior spinal artery, hemodynamic vertebrobasilar circulatory insufficiency, collateral channels, angioplasty, ischemia

\section{Introduction}

Proximal vertebral artery (VA) occlusion is usually compensated by anastomotic flow to the upper part of the artery via the deep cervical, thyrocervical, occipital, and ascending pharyngeal arteries or reflux from the circle of Willis via the posterior communicating artery. ${ }^{3)}$ Occlusion or severe stenosis of the unilateral VA tends to be asymptomatic if there is sufficient flow through the contralateral VA. ${ }^{7}$ On the other hand, patients with bilateral distal VA occlusions are not generally supposed to have such compensatory collateral channels, so occlusion in these patients may subsequently lead to the anterior spinal artery (ASA) syndrome. ${ }^{11,18)}$ However, the ASA may conversely be essential in supplying blood to the posterior circulation system under such severe conditions. ${ }^{5}$ )

We report two cases of retrograde flow through the ASA from the cervical VA to the intracranial distal VA because of disrupted perfusion from the bilateral VAs.

\section{Case Reports}

Case 1: A 76-year-old man with a 10-year history of diabetes and hypertension was transferred to our hospital on August 16, 2006, with a diagnosis of cerebellar infarction. No neurological abnormalities were noted except for mild dysarthria. Diffusionweighted magnetic resonance (MR) imaging revealed hyperintensity spots on the bilateral middle cerebellar peduncles (Fig. 1A). Left common carotid angiography revealed contrast filling of the midbasilar artery from the posterior communicating artery (Fig. 1B). Vertebral angiography revealed complete occlusion at the intracranial level just before the posterior inferior cerebellar artery (PICA) orifice on the right (Fig. 1C), and at the extracranial level on the left, with reversal of blood flow through the ASA arising from the left radicular artery (Fig. 1D-F). The patient was treated for 14 days with drip in-

Received September 8, 2008; Accepted March 9, 2009

Author's present address: H. Yamakawa, M.D., Department of Neurosurgery, Gifu Municipal Hospital, Gifu, Japan. 


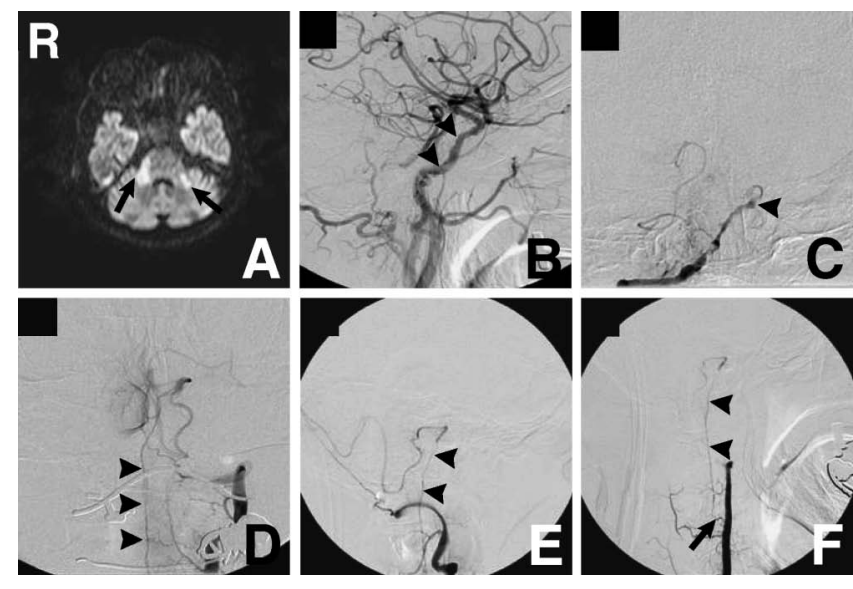

Fig. 1 Case 1. A: Diffusion-weighted magnetic resonance image of the middle brainstem and cerebellum showing lateral hyperintensity spots on both middle cerebellar peduncles (arrows). B: Left common carotid angiogram, lateral view, showing contrast filling of the mid-basilar artery from the posterior communicating artery (arrowheads). C: Right vertebral angiogram, anteroposterior (AP) view, showing the occluded vertebral artery just before the posterior inferior cerebellar artery orifice (arrowhead). D, E: Left vertebral angiograms, AP (D) and lateral (E) views, showing the anterior spinal artery (arrowheads) filled in the retrograde direction, and providing collateral support to the ipsilateral posterior inferior cerebellar artery. F: Left vertebral angiogram, lateral view, at the cervical level showing the anterior spinal artery (arrowheads), arising from the radicular artery (arrow), and ascending the ventral aspect of the cord as a collateral flow to the basilar artery.

travenous infusion of edaravone and 7 days of argatroban. He recovered almost completely within one month.

Case 2: A 48-year-old man developed vertigo, nausea, and vomiting on September 10, 2007. On admission, his neurological state was scored as 14 points on the Glasgow Coma Scale (E-3, V-5, M-6) with right hemiparesis. Diffusion-weighted MR imaging revealed multiple hyperintensity spots in the bilateral cerebellar hemispheres (Fig. 2A). Left common carotid angiography revealed exclusive contrast filling of the top of the basilar artery (Fig. 2B). Vertebral angiography revealed complete occlusion at the extracranial level on the left (Fig. 2C), and at the intracranial level just before the PICA orifice on the right, with reversal of blood flow through the
ASA (Fig. 2D, E). The patient was immediately treated with drip intravenous infusion of argatroban and low molecular weight dextran. Over the next 6 hours he lapsed into a coma, scored as 7 points on the Glasgow Coma Scale (E-1, V-2, M-4), with generalized hyperreflexia, pin-point pupils, and ataxic respiration. The absence of evidence of hydrocephalus on MR imaging led us to assume that his neurological deterioration was paralleled by the progressive hypoperfusion to the brainstem, although his neurological state was refractory to the induced hypertension caused by dopamine administration. Threedimensional computed tomography angiography showed severe calcified lesions at the occlusion site of both VAs (Fig. 2F), so we performed direct angioplastic surgery including right superficial temporal artery (STA) to superior cerebellar artery anastomosis, rather than the endovascular approach. Follow-up angiography 2 weeks later showed abundant contrast filling to the basilar artery via the anastomotic STA (Fig. 2G) as well as reduced reversal flow of the ASA. Postoperative MR imaging obtained 1 month later showed small infarctions in the brainstem and right cerebellar hemisphere (Fig. 2H). The patient became almost self-ambulant 3 months later.

\section{Discussion}

The ASA arises from the distal VA, courses medially to unite with the contralateral counterpart, and then courses inferiorly to supply the central part of the anterior two-thirds of the spinal cord. The mean outer diameter of the ASA is 0.7-0.8 mm. ${ }^{1)}$ Antegrade flow through the ASA has been demonstrated angiographically in 3 of 200 cases, ${ }^{20)} 24 \%,{ }^{2)}$ or $51 \%$ of the cases examined, ${ }^{17)}$ but usually requires more sophisticated techniques and facilities. ${ }^{2)}$ The ASA is very long and has numerous segmental connections at multiple levels, so is an important potential pathway for collateral arterial flow. ${ }^{4)}$ In such cases, pathological reversals of blood flow direction in the spinal cord arteries occur under peculiar conditions. ${ }^{4,5,7)}$ One of the most common reversals of flow takes place after the occlusion of both VAs before/after their penetration into the endocranium. A total of 12 such cases have been reported including our cases (Table 1).8,9,13,14,21) The patients were 7 males and 5 females aged from 28 to 81 years (mean 60.9 years). The treatment was conservative in 6 cases, endovascular angioplasty in 4 cases, and direct surgery in one case.

The interruptions in blood supply created by VA occlusions and the absence of collateral circulation through the posterior communicating artery may 

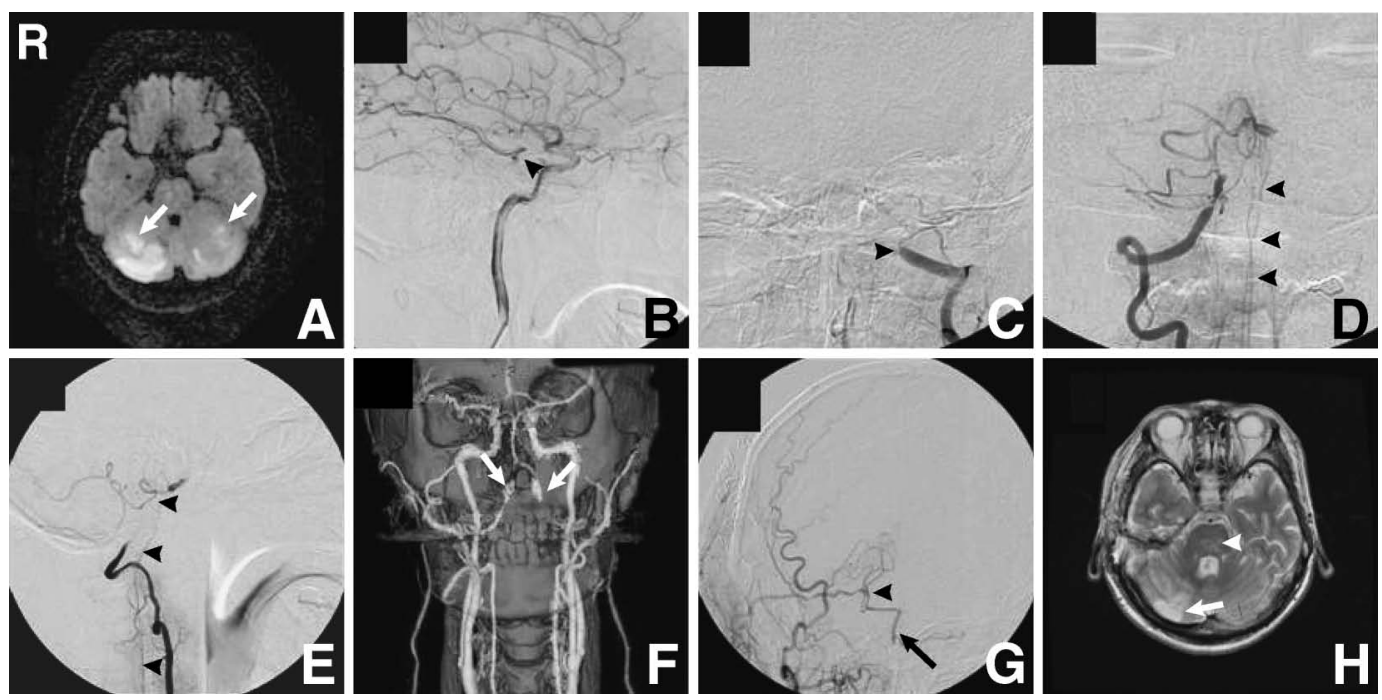

Fig. 2 Case 2. A: Diffusion-weighted magnetic resonance (MR) image of the middle brainstem and cerebellum showing multiple hyperintensity spots on both cerebellar hemispheres (arrows). B: Left common carotid angiogram, lateral view, showing contrast filling of the bilateral posterior cerebral arteries from the posterior communicating artery (arrowhead). C: Left vertebral angiogram, anteroposterior (AP) view, showing the occluded vertebral artery at the extracranial level (arrowhead). D, E: Right vertebral angiograms, AP (D) and lateral (E) views, showing the anterior spinal artery (arrowheads) filled in the retrograde direction, and providing collateral support to the ipsilateral posterior inferior cerebellar artery. F: Preoperative three-dimensional computed tomography angiogram showing severe calcifications in the occluded bilateral vertebral arteries (arrows). G: Postoperative right common carotid angiogram, AP view, showing contrast filling of the mid-basilar artery (arrow) via the patent anastomotic artery (arrowhead). H: Follow-up axial $\mathrm{T}_{2}$-weighted MR image showing small infarcted areas in the pons (arrow) and right cerebellar hemisphere (arrowhead).

cause flow reversal in the ASA, but little is known about the clinical implications of this type of flow reversal. The reported cases share certain similarities in that no large territorial infarction with mass effect or fatal brainstem infarction was observed, and no deaths occurred, but the delicate balance between the extent of perfusion via the ASA and the degree of collateral supply from the posterior communicating artery varies considerably from patient to patient. ${ }^{13)}$ Based on the angiographical analysis in our 2 cases, the occurrence of neurological deterioration seemed to parallel the development of the total blood supply from the anterior circulation system. However, the angiographical evaluation is far from being adequate to predict the outcome, as shown in Table 1. The period from the unilateral VA occlusion to the contralateral VA occlusion is also essential, since this must affect the total maturity of the collateral flow systems. The presence of an anatomical variant of the ASA also makes the clinical entities more complicated. ${ }^{15}$ )

Advanced development of the ASA might generally have advantageously reduced the likelihood of an ischemic event in these patients. Even in patients undergoing therapeutic occlusion of the VA for dissecting aneurysms, examining the ASA may be useful for predicting the likelihood of the lateral medullary syndrome developing in patients without a PICA or with a low origin PICA, ${ }^{12)}$ because the ASA may be involved in preventing the propagation of thrombus in the VA distal to the site of occlusion and supplying blood to its perforating arteries in such high-risk patients. However, evidence that the ASA cannot provide absolute protection can be seen in Table $1 .^{8,9,13,14,21)}$

Symptomatic, angiographically defined basilar artery occlusion and bilateral distal VA occlusions are associated with a mortality rate as high as $70 \%$ and significant morbidity in survivors. ${ }^{6}$ Current knowledge clearly suggests that the prognosis is grave in symptomatic patients with significant distal VA and basilar artery disease, and prompt restoration of blood flow preferably by endovascular angioplasty improves the outcome. ${ }^{6,10,16)}$ In our Case 2, the severe calcified lesions at the occlusion site contraindicated endovascular angioplasty. The surgical 
Table 1 Summary of reported cases of bilateral vertebral artery occlusions with collateral anterior spinal artery (ASA) channels

\begin{tabular}{|c|c|c|c|c|c|c|c|c|c|}
\hline $\begin{array}{l}\text { Case } \\
\text { No. }\end{array}$ & $\begin{array}{l}\text { Author } \\
\text { (Year) }\end{array}$ & $\begin{array}{l}\text { Age } \\
\text { (yrs) }\end{array}$ & Sex & Presentation & $\begin{array}{l}\text { Perfusion } \\
\text { via ASA }\end{array}$ & $\begin{array}{l}\text { Collateral } \\
\text { supply } \\
\text { from } \\
\text { PcomA }\end{array}$ & Treatment & Comment & Outcome* \\
\hline 1 & $\begin{array}{l}\text { Karasawa } \\
\text { et al. } \\
(1972)^{14)}\end{array}$ & 28 & $\mathrm{~F}$ & $\begin{array}{l}\text { headache, } \\
\text { tinnitus, } \\
\text { vomiting }\end{array}$ & $\begin{array}{l}\text { total BA } \\
\text { system }\end{array}$ & nil & conservative & $\begin{array}{l}\text { reversed ASA flow } \\
\text { filled BA trunk }\end{array}$ & $?$ \\
\hline 2 & $\begin{array}{l}\text { Uchiyama } \\
\text { et al. } \\
(1995)^{21)}\end{array}$ & 66 & $\mathrm{~F}$ & $\begin{array}{l}\text { vertigo, } \\
\text { vomiting }\end{array}$ & part of BA & nil & conservative & & GR \\
\hline 3 & $\begin{array}{l}\text { Garnier } \\
\text { et al. } \\
(2003)^{8)}\end{array}$ & 60 & $\mathrm{M}$ & $?$ & $\begin{array}{l}\text { total BA } \\
\text { system }\end{array}$ & $?$ & conservative & $\begin{array}{l}\text { reversed ASA flow } \\
\text { filled BA trunk }\end{array}$ & $?$ \\
\hline 4 & $\begin{array}{l}\text { Hott et al. } \\
\qquad(2004)^{9)}\end{array}$ & 68 & M & $?$ & $\begin{array}{l}\text { total BA } \\
\text { system }\end{array}$ & $?$ & $?$ & $\begin{array}{l}\text { reversed ASA flow } \\
\text { filled BA trunk } \\
\text { on MR angiog- } \\
\text { raphy }\end{array}$ & $?$ \\
\hline 5 & $\begin{array}{l}\text { Kang et al. } \\
(2007)^{13)}\end{array}$ & 62 & $\mathrm{~F}$ & $\begin{array}{l}\text { dizziness, } \\
\text { gait } \\
\text { disturbance }\end{array}$ & $\begin{array}{l}\text { PICA and } \\
\text { rt AICA }\end{array}$ & $\begin{array}{l}\text { bil SCA } \\
\text { filling }\end{array}$ & $\begin{array}{l}\text { IA thrombolysis } \\
\text { with stent- } \\
\text { assisted } \\
\text { angioplasty }\end{array}$ & $\begin{array}{l}\text { reversed flow of } \\
\text { ASA disappeared } \\
\text { after recanali- } \\
\text { zation }\end{array}$ & MD \\
\hline 6 & & 64 & M & $\begin{array}{l}\text { rt hemiparesis, } \\
\text { rt facial nerve } \\
\text { palsy }\end{array}$ & part of BA & nil & $\begin{array}{l}\text { IA thrombolysis } \\
\text { with stent- } \\
\text { assisted } \\
\text { angioplasty }\end{array}$ & $\begin{array}{l}\text { reversal of ASA } \\
\text { flow direction } \\
\text { after recanali- } \\
\text { zation }\end{array}$ & MD \\
\hline 7 & & 75 & $\mathrm{~F}$ & $\begin{array}{l}\text { lt hemiplegia, } \\
\text { lt facial nerve } \\
\text { palsy }\end{array}$ & $\begin{array}{l}\text { not } \\
\text { perfused }\end{array}$ & $\begin{array}{l}\text { BA trunk } \\
\text { filling }\end{array}$ & conservative & & VS \\
\hline 8 & & 63 & $\mathrm{~F}$ & $\begin{array}{l}\text { dizziness, } \\
\text { gait ataxia }\end{array}$ & $\begin{array}{l}\text { not } \\
\text { perfused }\end{array}$ & $\begin{array}{l}\text { bil SCA } \\
\text { filling }\end{array}$ & $\begin{array}{l}\text { stent-assisted } \\
\text { angioplasty }\end{array}$ & $\begin{array}{l}\text { reversal of ASA } \\
\text { flow direction } \\
\text { after recanali- } \\
\text { zation }\end{array}$ & GR \\
\hline 9 & & 40 & M & $\begin{array}{l}\text { dizziness, } \\
\text { gait ataxia }\end{array}$ & $\begin{array}{l}\text { PICA and } \\
\text { rt AICA, } \\
\text { lt AICA }\end{array}$ & nil & conservative & $\begin{array}{l}\text { increased perfu- } \\
\text { sion through } \\
\text { ASA after } \\
\text { occlusion }\end{array}$ & MD \\
\hline 10 & & 81 & $\mathrm{M}$ & $\begin{array}{l}\text { quadriparesis, } \\
\text { aphasia }\end{array}$ & $\begin{array}{l}\text { not } \\
\text { perfused }\end{array}$ & nil & $\begin{array}{l}\text { IA thrombolysis } \\
\text { with stent- } \\
\text { assisted } \\
\text { angioplasty }\end{array}$ & $\begin{array}{l}\text { reversal of ASA } \\
\text { flow direction } \\
\text { after recanali- } \\
\text { zation }\end{array}$ & VS \\
\hline 11 & $\begin{array}{l}\text { Present } \\
\text { Case } 1\end{array}$ & 76 & M & dysarthria & lt PICA & $\begin{array}{l}\text { BA trunk } \\
\text { filling }\end{array}$ & conservative & & GR \\
\hline 12 & $\begin{array}{l}\text { Present } \\
\text { Case } 2\end{array}$ & 48 & $\mathrm{M}$ & $\begin{array}{c}\text { consciousness } \\
\text { disturbance }\end{array}$ & rt PICA & $\begin{array}{l}\text { BA top } \\
\text { filling }\end{array}$ & $\begin{array}{l}\text { STA-SCA } \\
\text { anastomosis }\end{array}$ & $\begin{array}{l}\text { reversed flow of } \\
\text { ASA resided }\end{array}$ & MD \\
\hline
\end{tabular}

*According to Glasgow Coma Scale. AICA: anterior inferior cerebellar artery, BA: basilar artery, GR: good recovery, IA: intraarterial, MD: moderate disability, MR: magnetic resonance, PcomA: posterior communicating artery, PICA: posterior inferior cerebellar artery, SCA: superior cerebellar artery, STA: superficial temporal artery, VS: vegetative state.

indications remain unclear, ${ }^{19)}$ especially in patients with acute deterioration caused by brainstem ischemia. We would like to emphasize the clinical significance of acute anastomotic surgery, which may be essential in the restoration of blood flow in selected patients. Until methods to evaluate the precise and simultaneous ischemic damage caused by VA occlusion are developed, we should incorporate therapeutic modalities including angioplasty as early in the course as possible, especially in a patient with clinical progression such as our Case 2. Also, these reversals of flow may cause the 'steal' phenomenon, resulting in some degree of cord ischemia. ${ }^{4}$

\section{References}

1) Akar ZC, Dujovny M, Gomez-Tortosa E, Slavin KV, Ausman JI: Microvascular anatomy of the anterior surface of the medulla oblongata and olive. J Neurosurg 82: 97-105, 1995

2) Billewicz O, Heldt $\mathrm{N}$ : The visualization of the anterior spinal artery and its blood-stream direction during brachial vertebral angiography. Neuroradiology 2: 46-51, 1971

3) De Clerck M, Paemeleire K, Achten E, Van Langenhoven P, De Bleecker J, De Reuck J: A pure sensorimotor stroke due to cervical vertebral artery occlusion. Acta Neurol Belg 103: 225-227, 2003

4) Di Chiro G, Fried LC: Blood flow currents in spinal 
cord arteries. Neurology 21: 1088-1096, 1971

5) Doppman JL, Di Chiro G, Glancy DL: Collateral circulation though dilated spinal cord arteries in aortic coarctation and extraspinal arteriovenous shunts. An arteriographic study. Clin Radiol 20: 192-197, 1969

6) Ezaki Y, Tsutsumi K, Onizuka M, Kawakubo J, Yagi N, Shibayama A, Toba T, Koga H, Miyazaki $\mathrm{H}$ : Retrospective analysis of neurological outcome after intra-arterial thrombolysis in basilar artery occlusion. Surg Neurol 60: 423-430, 2003

7) Fisher CM: Occlusion of the vertebral arteries. Causing transient basilar symptoms. Arch Neurol 22: 13-19, 1970

8) Garnier P, Januel AC, Demasles S, Michel D: Collateralization of vertebral arteries. Neurology 60: 720, 2003

9) Hott JS, Vishteh G, Wallace R, Dean BL, Spetzler RF: Anterior spinal artery supplying posterior circulation. Neurology 62: 468, 2004

10) Imai K, Mori T, Izumoto $H$, Kunieda $T$, Takabatake $\mathrm{N}$, Yamamoto S, Watanabe $\mathrm{M}$ : Transluminal angioplasty and stenting for intracranial vertebrobasilar occlusive lesions in acute stroke patients. AJNR Am J Neuroradiol 29: 773-780, 2008

11) Johkura K, Joki H, Johmura Y, Momoo T, Kuroiwa Y: Combination of infarctions in the posterior inferior cerebellar artery and anterior spinal artery territories. J Neurol Sci 207: 1-4, 2003

12) Kado K, Hirai S, Kobayashi S, Kobayashi E, Yamakami I, Uchino Y, Saeki N, Yamaura A: Potential role of the anterior spinal artery in preventing propagation of thrombus in a therapeutically occluded vertebral artery: angiographic studies before and after endovascular treatment. Neuroradiology 44: 347-354, 2002

13) Kang HS, Han MH, Kim SH, Kwon OK, Roh HG, Ko YC: Anterior spinal artery as a collateral channel in cases of bilateral vertebral arterial steno-occlusive diseases. AJNR Am J Neuroradiol 28: 222-225, 2007

14) Karasawa J, Terano M, Nishikawa M, Kyoi K, Kikuchi H: [Case of persistent bilateral carotid-basilar anastomoses (primitive otic artery and primitive trigeminal artery) with multiple vascular anomalies]. No To Shinkei 24: 91-98, 1972 (Jpn)

15) Kawamura J, Matsubayashi K, Fukuyama H, Kitanaka H: Paired anterior spinal arteries in a case of locked-in syndrome. Neuroradiology 22: 107-110, 1981

16) Kirton A, Wong JH, Mah J, Ross BC, Kennedy J, Bell K, Hill MD: Successful endovascular therapy for acute basilar thrombosis in an adolescent. Pediatrics 112: 248-251, 2003

17) Schechter MM, Zingesser LH: The anterior spinal artery. Acta Radiol Diagn (Stockh) 3: 489-496, 1965

18) Suzuki K, Meguro K, Wada M, Nakai K, Nose T: Anterior spinal artery syndrome associated with severe stenosis of the vertebral artery. AJNR Am J Neuroradiol 19: 1353-1355, 1998

19) Terai Y, Fujimoto S, Kawauchi M, Kinugasa K, Nishimoto A: [Superficial temporal to superior cerebellar artery anastomosis for rostral brain stem infarction]. No Shinkei Geka 14: 1347-1352, 1986 (Jpn, with Eng abstract)

20) Thomas LM, Hardy WG, Lindner DW, Gurdjian ES: Retrograde brachial angiography in cerebrovascular disease. Arch Neurol 7: 339-346, 1962

21) Uchiyama S, Yoshida M, Shimizu H: [MR imaging of the anterior spinal artery in a case of bilateral vertebral arterial occlusion]. Rinsho Shinkeigaku 35: 60-63, 1995 (Jpn, with Eng abstract)

Address reprint requests to: Haruki Yamakawa, M.D., Department of Neurosurgery, Gifu Municipal Hospital, 7-1 Kashima-cho, Gifu 500-8513, Japan. 